\title{
LIBRARY PROVISION TO THE TAMIL COMMUNITY IN SINGAPORE
}

\author{
Malarvele Ilangovan \\ Nanyang Technological University \\ School of Communication and Information \\ Division of Information Studies \\ Nanyang Circle \\ Singapore 639819 \\ ilangovan@nlb.gov.sg \\ Susan E. Higgins \\ Charles Sturt University \\ School of Information Studies \\ Boorooma Street \\ Wagga Wagga NSW 2678 \\ Australia \\ shiggins@csu.edu.au
}

\begin{abstract}
This study explores the provision of public library services to the Tamil Community through the National Library Board of Singapore's system of public libraries. Results of the study are analyzed and implications for services deduced through focus group interactions and researcher observations. The study concludes that improvement is needed in collections, facilities, programming, and services, particularly in the area of provision to young people. Focus group participants also propose an Internet portal in Tamil. Many indicate that the library could, through facilitating the reading and use of the Tamil language, help in promoting the usage of the Tamil language in Singapore. The recognition of Tamil as a national language of Singapore has given the Tamils intrinsic satisfaction because the language provides them with a living link to their ethnic culture. They believe the library can help them regain their cultural identity and also assist them in repositioning themselves positively in Singaporean society. The contribution of this study to the professional literature is the idea of cultural identity being central in public library services to special user groups.
\end{abstract}

\section{INTRODUCTION}

As social institutions, public libraries have always had the responsibility of assimilating minority groups into the mainstream society. The Library 2000 Report (1992) of Singapore described this responsibility in the following way: "there is a need to establish specialised information services to preserve, promote the literary heritage and to encourage local communities to flourish and develop their own unique characteristics" (p.8). A steady drop in the number of Tamil speaking households from 52 percent of all Indian households in 1980 to 44 percent in 1990 exacerbates the problem of preserving this language's unique characteristics (Nirmala, 1995). Such statistics may indicate a need to improve the provision of library services to the Tamil community in Singapore.

Today the National Library Board of Singapore operates a system of the National Reference Library, two Regional Libraries, 18 Community Libraries and 46 Community Children's Libraries. Currently, 160,197 books and 17,351 serials are available in Tamil (http://www.nlb.gov.sg). According to the reading survey conducted by Survey Research Singapore in 1992/1993 of book readers above 13 years old, 2 percent read in Tamil 
(Building the Tamil Collection, internal NLB report, 1997). The Tamil loans constituted an average of 1.16 percent of the total loans as compared to 2.69 percent of the total collection in the National Library Board from financial year 1995 to 1998 . Within the Tamil collection, 56.44 percent were adult books, 38.31 percent children's books, and 5.25 percent young people's books. Among the Tamil readers, 73 percent were adults, 24.35 percent were children, and 2.65 percent were young people. The most popular books were fiction, health and fitness, computer, and self-improvement. Tamil magazines were also among the favourites (National Library Report, 1999).

The following research questions formed the basis of this study:

How is the Tamil collection being used at the National Library Board, Singapore public libraries, and for what purpose?

What types of Tamil materials do Tamil users read at the National Library Board, Singapore public libraries?

How can the National Library Board, Singapore public libraries provide better collections and services to the Tamils?

Have the National Library Board, Singapore public libraries been successful in attracting Tamil users?

The study was limited to the Tamil community and did not include the Indian community at large. The Tamil community represents 64 percent of the Indian population in Singapore.

\section{LITERATURE REVIEW}

\section{Library Services to Ethnic Minorities}

A minority group of people such as the Tamil-speaking Singaporeans differ in some ways from the principal group in a society in that they are small in numerical strength and have fewer economic, political, and social opportunities than members of the dominant groups. It is the belief of some researchers that libraries should help the ethnic community regain their cultural identity, no matter how small the community, because libraries are supported by the tax dollars of the whole community (Carroll, 1985).

\section{The Tamil Community}

The Tamil Indian community accounts for approximately 7 percent of the total population in Singapore, and 64 percent of that community are Tamils. Tamil education was pre-eminent in Singapore as early as 1948 (Singh, 1982). A Tamil library was established in 1951 in Singapore (Tamil Murasu, 1951, March 4, p.6), and the status of the Tamil language gained prominence in 1966 when the second-language requirements of the government's bilingual policy pushed the relevance and the usage of the Tamil language (Nirmala, 1995).

\section{Provision of Tamil Script Library Materials in Singapore}

The provision of library materials in Chinese, Malay, and Tamil was granted in the early days of Singapore. Because Tamil was the mother tongue language, established at the time of self-government in 1959, it "acted as a transmitter of Asian values and served as means of cultural identity" (Martland, 1987, p.5). Today the Tamil tongue is used in government campaigns, public education programs, and at public functions.

The Raffles National Library in Singapore in 1960 was the first public library that provided collections in three important local languages on a large scale. At that time, the greatest problem faced by the National library was the recruitment of a sufficient number of qualified bilingual librarians to meet the demands of the vernacular materials (Anuar, 
1960).

A significant Tamil collection exists at the Umar Pullavar Tamil Language Centre, which serves students studying Tamil as a second language. Students are allowed to borrow reference books for their projects in schools, and this library has promoted usage through various library activities, for example, a presentation entitled "The Usage of Library In Second Language” (Umar Pulavar Tamil Language Centre, Souvenir Magazine, 1989, p. 20).

\section{METHODOLOGY}

\section{Focus Group Interview As a Research Technique}

The methodology employed in this study was the focus group interview technique. According to Connaway (1996), "focus group methodology lends itself well to community analysis and the evaluation of library services and resources" (p. 236). This study followed Gorman and Clayton's (1997) recommendation that a focus group be composed of six to twelve participants with a facilitator or a moderator to guide and motivate the participants in an effort to gain an understanding of their attitudes and perceptions relevant to a particular topic of discussion.

A limitation of the focus group, however, lies in the difficulties of interpreting the immense data. This pool of information must be deciphered carefully to avoid quoting comments out of context. Also, the researcher may arrive at premature conclusions because the moderator can influence the respondents by probing to attain the desired answers.

\section{Focus Group Participants}

The respondents were all regular library users who had patronised the Tamil collection in the libraries of the National Library Board of Singapore. The youngest interviewee was 14 years old; the eldest was 65 . All of the participants are Tamils ethnically; have studied the Tamil language in schools; and are able to converse, read, and write in Tamil. There were five males and seven females.

The participants were recruited through the researcher's contacts from civic and media organizations, recommendations from former colleagues, library users from community libraries, and others recommended by personal friends.

\section{Conducting the Sessions}

The sessions were conducted in English, and each meeting lasted no more than two hours. Participants were requested to wear nametags and mingle with one another before the meeting began. At the start of the sessions, the researcher explained the objectives of the focus group meetings and how the participants as regular users of the library could benefit from the meetings. All names were held confidential.

The researcher used an interview guide to direct the discussion. Open-ended questions were designed, pre-tested, and piloted by non-selected investigators. These questions became useful in manipulating and stimulating discussion when responses opened new avenues for data collection. The researcher used the emerging and recurrent themes from the first discussion to facilitate the second and third focus group sessions while remaining on the topic. Frequently, one participant's comment led to chains of response from the others.

\section{Data Analysis}


The researcher transcribed the recorded transcripts after each session and made phone calls or sent e-mail messages to several participants to clarify some responses. As the information collected was extensive, a non-linear, reiterative process of returning to the data became necessary. Moreover, the researcher employed emerging themes and patterns from the data as a means of re-organising the information gathered. Themes and patterns defined a set of coding categories based on the actual data, i.e., the answers posed to the questions in the interview guide. This coding factor represented thematically cohesive content found within the narratives and, once analysed, provided a data reduction technique (Moen \& McClure, 1997). Qualitative information concerning expected user benefits of Tamil collections in Singapore's public libraries, lessons learned through experience, and perceived barriers or threats to the success of the Tamil collection were all noted.

\section{Reading Habits}

Many participants rated reading as one of their favorite pastimes and indicated that their reading inclined towards English materials. All twelve participants visited the library at least once a month, demonstrating that all of them were library users. This study concurred with the research done by Mani and Gopinath (1983) on linguistic trends. They stated that "each population census has clearly indicated literacy rates are higher among the Indians when compared to Chinese, Malays and others in Singapore" (p.105).

\section{Evaluation of Tamil Collection}

\section{Tamil Magazines and Newspapers}

Participants made suggestions for the use of the Tamil collections as a whole. For example, eight rated Tamil magazines as their favourite format and requested that more titles be added to the magazine collection.

The participants also proposed that all magazines be placed in the lending section instead of being located in the reference collection. In order to extend the access of such popular Tamil magazines as the Indian Movie News, some libraries have placed them in the reference collection for internal library use. This allows more users to read the latest issues. The researcher proposed that more varieties be added to the Tamil magazine collection.

The participants considered newspaper reading unpopular. In fact, there was only one participant who read the Tamil newspaper to keep abreast of developments in the Tamil community. The researcher deduced that more detailed information is easily available in the English newspapers and that perhaps the Tamil newspaper is not packaged attractively enough to lure young readers. An improvement in the physical presentation and quality of newspaper might attract readers.

\section{Tamil Fiction Books}

Some participants read mostly fiction in Tamil from such popular authors as Mu Va, Agilan, and Kalki. One participant suggested that the library buy more copies of these authors' books while another proposed that more varieties of popular fiction written by young authors would be preferable to those by old writers. 
One participant suggested that the library highlight local authors to combat the more India-based novels and stories, which the locals may find difficult to relate to. To address this problem, the library might encourage local publishing output for the Tamil community; however, whether a small population base such as that of the Tamil community could justify a major publishing effort is another point of consideration.

\section{Tamil Non-Fiction Books}

Only five participants read the adult Tamil non-fiction books, saying they needed to read them for information they could not gather from English books. Some participants felt that information on Indian art, literature, and religion was richer in the ethnic-based language.

One participant rated the contents in the Tamil computer magazines to be on a par with the English magazines. He concluded that it was easier to read in Tamil for the information he needed than to read it in English and then to translate it.

Most participants were not satisfied with the adult non-fiction books as there is a real need to enlarge the collection. Moreover, there is also a need to highlight the Tamil adult non-fiction books. Many Tamil users have the notion that the content or information presented in the Tamil books is inferior to that in English books. Then again, it can be argued that the Tamil books may be poorly packaged but need not suffer from a lack of content-rich materials.

\section{Children's Collections}

Both the fiction and non-fiction Tamil book collections needed to be greatly improved. The children's collection was small and contained books with poor quality paper and bindings. They appeared wordy and used small-print fonts.

According to the National Readership Survey conducted by Forbes Research, Indians constituted the highest proportion of those who read English newspapers with understanding and comprised the lowest proportion of those who could read their mothertongue language or Tamil as compared to the Chinese and the Malay (Development of the NLB Indian Collection, NLB Internal Report). Improving the children's collection is the first step in reversing this trend.

The participants offered such useful suggestions as the translation of popular English works such as folklore, fairytales, and other stories into Tamil, retaining the illustrations from the English books. They believed that this would help to address the shortage of colorful and attractive books. Moreover, many who are familiar with the English language can relate to the stories better when read in Tamil.

Another recommendation put forth by the focus group was to get writers of children's literature from all over "the world to write in Tamil and then publish them either in print or by electronic media." There are many Tamil writers who live in and out of India who can be a good resource to develop the Tamil children's literature collection.

Four participants felt that the library could develop non-print materials for children in Tamil. Perhaps the library could develop Tamil audio and visual materials as well as Internet resources. With a proper provision of materials in Tamil for children, it would encourage them to use the collections and patronise the Tamil collections.

One suggestion was to recruit a Tamil-speaking children's librarian in all the libraries to concentrate on collections and services pertaining to Tamil. Presently, the National Library 
Board is developing children's services in Woodlands Regional Library. The researcher recommends that services for the Tamil children be included in this effort as children's services would challenge them to read, learn, use, and appreciate Tamil.

\section{Young People's Collections}

Many participants rated the young people's collections as the poorest among the Tamil collections, mainly because these collections failed to meet the educational, functional, recreational, and personal needs of young people. There is also a dearth of materials appropriate for the young. Moreover, most books from these collections are placed with the adult collections, making their accessibility even more difficult. Participants suggested that the library include more interesting subject areas such as Tamil music, fashion, and cinema to attract the Tamil youths. Many young people use the Tamil collections only if they have to do school projects. The challenge for the library is to retain these users by providing materials that will continually attract them.

\section{Reference Collections}

Most of the participants said that the reference collections in Tamil did not meet their intellectual needs. Research and academic papers, seminar papers, conference proceedings, speeches, scholarly publications, and theses in Tamil need to be acquired.

One other participant recommended adopting an exchange of information program with some of the best Tamil libraries in the world. Another wished to see Singapore become the hub for "Tamil language in the region" by developing reference collections of world class standards. One participant stated, "The reference collections in Tamil must be a showcase- something that shows our history, culture, traditions and so forth."

\section{Bilingual Collection}

The participants stated that they needed the bilingual collection to enable non-Indian readers to acquire knowledge about their ethnic group. Providing English materials about the Indian community would be useful in helping the rest of the population comprehend the minority segment. The bilingual collection would help create deeper understanding among the various sub ethnic groups in the Indian community and create more tolerance.

\section{Audio and Video Collection}

The participants suggested that the National Library Board could acquire a non-print collection that depicts the richness of the ancient Tamil tradition. They felt that such a provision would also help other segments of the population to respect each other's culture and traditions.

One participant would like to see the development of an oral history collection in Tamil. Such a collection would be timely, especially when the elderly Tamil population consists of the first generation of immigrants.

Implementing Tamil videos for lending is another way to add value to the services the library can offer to the Tamil community. At the moment, the service is available only in English, Chinese, and Malay.

\section{Collection of the Fine Arts}

Some participants expressed interest in developing music, dance, and art collections for 
Tamil users. It was agreed that the library, by displaying mural collections, could promote ethnic values. Knowledge of the Indian civilization's paintings and musical instruments will help the Tamil community to regain their cultural values.

\section{Heritage Collection}

There is a dire need to develop the heritage collection. Indians, as early immigrants to Singapore, have contributed significantly to nation building. Information about the history of the Indian settlers-their culture, literary and art traditions-can be collected in a systematic manner in the library.

\section{Use of the Tamil Language}

Most participants agreed that the Tamil collections were flawed in many ways. They were not satisfied with the collections as a whole, including the classification and the location of these materials in the library. They also found the Tamil books unattractive, old, and outdated. The lack of materials in Tamil and the library's inadequacy in satisfying their information needs had invariably failed to encourage them to use the Tamil language progressively. This may have contributed to the decreasing usage of the Tamil language in Singapore. The 1990 population census showed that there was an 8 per cent drop in the number of Tamil speaking households compared to 1980. A three-year survey conducted from 1989-92 on Tamil language usage reinforced the drastic picture of the community losing touch with the Tamil language (Nirmala, 1995). The survey also revealed a trend among the Tamil community to use English at home to the exclusion of Tamil.

Four out of twelve participants said they would not read in Tamil even if they could. They found no leisure time to read, and Tamil was not relevant to them because it was difficult to read and they were not proficient. They added that not enough Tamil books were available that would interest them. On one hand, the community might cite the library for not promoting the Tamil language enough to sustain its extensive usage. On the other hand, there are other reasons for the low usage of the language. Mani and Gopinath (1983) noted that the Indian community in Singapore has not acknowledged Tamil as the intraethnic language. Tamil is only one of many Indian languages and cannot be regarded as the language of communication. Other Indians in Singapore are also very proud of their own languages such as Malaylam, Telegu, Punjabi, Gujerati, Sindhi, and Hindi and would like to keep their languages alive as well.

Perhaps many Tamils perceive the Tamil language as having little use in multilingual Singapore. Mani and Gopinath (1983) noted that the Tamils had belittled the value of the Tamil language as a result of their high participation in English-medium education.

There is indeed a mixed perception of the usage of Tamil in Singapore. While there is a decreasing usage of the Tamil language, it is nonetheless a functional language as it is recognized as one of the four official languages in Singapore and is used in government campaigns, public education programs, and public functions.

Further, Tamil is widely offered as a second language in most schools in Singapore (The Singapore Ministry of Education website-http://www.moe.com.sg/).

148 primary schools offer Tamil as a second language 76 secondary schools offer Tamil as a second language 5 Tamil language centers offer Tamil as a second language 5 secondary schools offer higher Tamil 
Out of twelve participants, eight felt the need to read in Tamil despite poor provisions and services to the Tamil community. The reasons cited were

Tamil is their mother tongue.

They have a need to keep in touch with the Tamil language.

They have a need to keep abreast of developments in the Tamil community.

They want to keep their roots and traditions alive.

It is a requirement to pass Tamil in school examinations.

They want to help their children read in Tamil.

They want to improve proficiency in the language.

They are fluent in Tamil.

They are Tamils.

All twelve participants felt that the library could do much more to stop the deterioration in the use of the Tamil language. Many expressed their opinion that by resource collection and service provision to the Tamil community, the library would not only help them regain their cultural identities but also assist them to reposition themselves positively in the society.

\section{General Perception of the Library}

The participants were generally satisfied with the collections and services provided by the library. They were impressed with the way the library had harnessed technology to bring about changes.

Some suggested that the library should extend its operating hours while others complained about the location of the books of their choice in the library.

\section{Recommendations to Improve Library Services to the Tamil Community}

Participants in the focus group noted that books for children were unattractive, the collection size was small, and the books were published with poor quality paper and inferior printing and binding compared with books in English. The absence of reviewing journals and other reference tools had further made the selection process of Tamil materials difficult. Special features such as indexes, bibliographies, and illustrations were lacking. Tamil book publishing tends to be unbalanced, especially in the area of non-fiction. While there is a preponderance of books on literature, there seems to be a dearth of books on computers, self-improvement, and other subjects.

Although the participants were generally satisfied with the library in the fulfillment of their information needs, those needs pertaining to the provision of library services to encourage the usage of Tamil were inadequately provided for.

Many participants suggested the following improvements:

To revamp the Tamil collection to tailor to the needs of the community

To have better promotion and outreach programs in Tamil

To encourage writing of book reviews

- To organize book displays

- To consolidate book lists

- To recruit Friends of the Library

- To organize community involvement programs

- To organize library talks

- To organize programs with the media 
- To organize programs for children

- To organize user orientation programs

- To conduct class visits

- To develop a portal for the Tamil community

- To have translation services

- To implement an online Tamil catalogue system

\section{Accessibility}

Many participants said that services to the Tamil community should be more accessible. It has been noted that a low number of Tamils visit the library. Perhaps they are either using Internet resources at home or buying their own books. The challenge to the library is to bring its services to the community.

\section{Mobile Libraries for Tamil Collections}

Participants stated that there are many elderly Tamils who are unable to use the library because they may be physically challenged. There may be others who belong to the lower income group and cannot afford to visit the library frequently. A mobile library where the charges can be subsidized by the civic organizations was suggested. One participant commented, "I really hope that the library can do something to help the Tamils who are poor, so poor that they cannot buy books of their own; these people need the library more than anyone of us."

\section{Home Delivery Services for Tamil Books}

The majority of the participants indicated their interest in home delivery services for Tamil books. They stated that it would be one good way to circulate the Tamil collection. Some said the library could even charge a nominal fee for the service.

\section{Internet Services in Tamil}

An electronic village or virtual community that can provide Internet resources would help the community to have links with the Tamil language. Via the Web, the library can interconnect with other resources in the Tamil language as well as libraries throughout the world with the best Tamil collections.

Eleven participants were in favor of this idea. They would like to be exposed to more electronic resources in Tamil. They felt that ongoing technological changes could result in higher levels of services to the Tamil community. The Tamil collection needs to keep abreast of technological advances or will have to risk being irrelevant to Tamil users. Many traditional and new forms of information in Tamil could be collected, stored, and transmitted in digital forms.

\section{One Regional Centre for Tamil Studies}

There is a dire need to consolidate all the Tamil resources in one place. Many participants would like to see a regional centre for Tamil studies. One participant stated, "There is [are] Chinese studies, Malay studies, but no Tamil studies in the local Universities." Another said, "There is no single Tamil book in the libraries of National University of Singapore."

One way to encourage the continued learning of the ethnic language is to provide resources in such higher institutions as universities. The findings of this study indicate a need to offer Tamil studies as a subject in the local universities. Mani (1993) stated that there is an urgent need to adopt a promotional policy of the Tamil language: "a systemic 
development of Tamil language as a literary studies [program] at the highest academic levels would uplift the status of the use of Tamil language" (p.115).

\section{Conclusion}

The findings suggest that there was no adequate provision of library services to the Tamil community and that such provision would enhance the use of Tamil language in Singapore by having a significant impact on the perceptions and expectations of the user.

\section{Conclusions Based on the Focus Group}

This study of the Tamil community's expectations of services designed for them concurs with the literature that provision of library services for the ethnic minority is essential in order to develop professional library service.

\section{Further Research}

Since there are myriad Indian languages in Singapore, the requirement to meet the language needs of all in the Indian community in Singapore is a concern for the future. The needs of those who are fluent and seek materials in other Indian languages such as Hindi and Punjabi will have to be addressed accordingly.

\section{REFERENCES}

Arasaratnam, Sinnappah. (1970). Indians in Malaysia and Singapore. Kuala Lumpur: Oxford University Press.

Anuar, Hedwig. (1960). The provision of books in Malay, Chinese and Tamil in Raffles National Library. Singapore, Malayan Journal, 1(1), 17-25.

Carroll, Roy. (1985). Multicultural library services: A New Zealand view. Libraries after 1984: Proceedings of the LAA/NZIA Conference, 360-366.

Connaway, L.S. (1996). Focus group interviews: A data collection methodology for decision making. Library Administration \& Management, 10(4), Fall, 231-239.

Gorman, G.E., \& Clayton, P. (1997). Qualitative research for the information professional: A practical handbook. London: Library Association Publishing.

Library 2000 : Investing in a learning nation. (1994). Report of the Library 2000 Review Committee. Singapore: SNP Publishers Pte Ltd.

Martland, Nicholas. (1987). Library Services to Ethnic Groups: The Singapore Experience. Singapore Libraries, 17, 3-11

National Library: Building the Tamil Collection. (1997). Unpublished report, National Library Board, Singapore.

National Library: Development of the NLB Indian Collection. (1999). Unpublished report, National Library Board, Singapore.

Nirmala, M. Tamil: Community acts to check its decline. (1995, June 4). The Sunday Times, p. 6. 
Mani, A. (1993). Indians in Singapore society. In Sandhu, K.S. \& Mani, A. (Eds.), Indian communities in Southeast Asia, 788-809. Singapore: Institute of Southeast Asian studies.

Mani, A., \& Gopinathan, S. (1983). Changes in Tamil language acquisition and usage in Singapore: A case of subtractive bilingualism. Southeast Asian Journal of Social Science, 11(1), 104-17.

Moen, W. E. \& McClure, C. (1997) An Evaluation of US GILS Implementation June 30, 1997 APPENDIX C-2 Focus Group Methodology Page 2.

www.unt.edu/wmoen/publications/gilseval/c2.pdf - Accessed January 2003.

National Library Board of Singapore. http://www.nlb.gov.sg

Accessed January 2003.

Sudhamani, S.R. (1982). Indians in Singapore. In Singh, Bahadur, I.J. (Ed), Indians in Southeast Asia, 89-97. New Delhi: India International Centre.

Tamil Library, (1951, March 4). Sunday Tamil Murasu, p. 6.

The Singapore Ministry of Education Website - http://www.moe.sg/.

[ 2001, February 12].

Umar Pulavar Tamil Language Centre Souvenir Magazine, (1989). Singapore: Umar Tamil Language Centre.

Westbrook, Lynn. (1999). Analysing community information needs: A holistic approach. Library Administration \& Management, 14(1), 26-30. 